DOI: $10.5902 / 1983465912230$

\title{
INOVAÇÃO DE VAREJO SUSTENTÁVEL: E-COMMERCE E COMÉRCIO JUSTO
}

\author{
SUSTAINABLE RETAIL INNOVATION: \\ E-COMMERCE AND FAIR TRADE
}

\author{
Recebido 01-12-2013 \\ Aceito 20-04-2014 \\ Lívia Tiemi Bastos ${ }^{1}$ \\ Paulo Roberto Feldmann² \\ Nuno Manoel Martins Dias Fouto ${ }^{3}$
}

\section{RESUMO}

Com os mercados progressivamente mais competitivos, prezar por um relacionamento de longo prazo com os consumidores é cada vez mais importante, tornando necessário olhar para eles com atenção ao embarcar em qualquer uma das tendências vigentes no varejo. O consumo, por sua vez, é fruto de um processo sociocultural, no qual são embutidos valores, princípios e preferências que condicionam as escolhas dos indivíduos. Tendo isso em vista, o objetivo deste estudo reside em investigar a inovação no contexto das atividades varejistas, sob a ótica da inovação sustentável. Em especial, o presente artigo busca estudar o comércio justo no âmbito das lógicas predominantes no varejo competitivo. A pergunta desta pesquisa é: uma parceria entre uma empresa varejista e um negócio social de comércio justo configura uma inovação sustentável? Para abordar a questão, a qual detém um caráter exploratório, um estudo de caso é proposto sobre o E-Solidário, uma parceria entre a Solidarium e o Walmart, que juntos têm como objetivo ser o maior canal de comércio justo no Brasil. Os dados obtidos indicam uma inovação de varejo sustentável como resultado dessa parceria entre as duas organizações, com benefícios para ambas.

Palavras-chave: Varejo; Comércio Justo; Negócio Social; Sustentabilidade; Parceria interorganizacional.

${ }^{1}$ Possui graduação em Ciências Econômicas pela Universidade Federal do Paraná - UFPR, mestrado em Administração pela Universidade de São Paulo - USP. Atualmente é doutoranda em administração pela Universidade de São Paulo - USP. São Paulo, São Paulo, Brasil. E-mail: liviatiemi@usp.br

2 Possui graduação em Engenharia pela Universidade de São Paulo - USP, mestrado e doutorado em Administração pela Fundação Getúlio Vargas - FGV. Atualmente é professor do departamento de Administração da Universidade de São Paulo - USP. São Paulo, São Paulo, Brasil. E-mail: feldmann@usp.br

${ }^{3}$ Possui graduação em Engenharia de Aeronáutica pelo Instituto Tecnológico de Aeronáutica- ITA, mestrado e doutorado em Administração pela Universidade de São Paulo - USP. Atualmente é professor do departamento de Administração da Universidade de São Paulo. São Paulo, São Paulo, Brasil. E-mail: nfouto@usp.br 


\section{ABSTRACT}

As markets became progressively more competitive, to cherish for a long-term relationship with consumers has been of a growing importance. This fact makes it necessary to look at them carefully as you embark on any of the current trends on retail. Consuming, in turn, is an activity that results of a socio-cultural process, in which are embedded values, principles and preferences that influence the choices. The research objective of this study is to investigate innovation in the context of retail activities, analyzing from the perspective of sustainable innovation. This study aims to particularly study fair trade under the prevailing logics in competitive retail. The research question is: does a partnership between a retailer and a fair trade social business sets as sustainable innovation? To address the issue, which has exploratory character, a case study is proposed on E-Solidário, a partnership between Walmart and Solidarium, which together aim to be the largest fair trade channel in Brazil. An innovation in sustainable retail was verified as a result of the partnership between the two organizations, with benefits for both.

Keywords: Retail; Fair Trade; Social Business; Sustainability; Interorganizational Partnership.

\section{INTRODUÇÃO}

O ambiente atual do varejo está marcado por três grandes tendências que influenciam a atuação dos grandes varejistas no mundo: práticas de fornecimento global, rotas multicanais para os mercados e inovação baseada em relacionamento (Ganesan et al., 2009). Com os mercados progressivamente mais competitivos, prezar por um relacionamento de longo prazo com os consumidores é cada vez mais importante, o que torna necessário atentar às suas necessidades ao embarcar em qualquer uma das tendências vigentes. O consumo, por sua vez, é fruto de um processo sociocultural, no qual estão embutidos valores, princípios e preferências que condicionam as escolhas dos indivíduos.

O consumidor final está cada vez mais atento aos atributos de sustentabilidade, considerando critérios éticos no seu processo de compras (Andorfer, Liebe, 2012) e mostrando interesse pelo que se passa nos bastidores da produção dos produtos (Töpfer, 2002). Sua percepção sobre o investimento do varejista em sustentabilidade afeta a imagem do varejista e sua propensão à compra de marcas específicas (Handelman and Arnold, 1999). Por essa razão, desenhar produtos e processos sustentáveis constitui-se em uma oportunidade para inovações no varejo (Reinartz et al., 2011).

Tendo isso em vista, o objetivo de pesquisa do presente estudo reside em investigar a inovação no contexto das atividades varejistas, sob a ótica da inovação sustentável. Em especial, o presente artigo busca estudar o comércio justo no âmbito das lógicas predominantes no varejo competitivo. A pergunta de pesquisa que se busca responder é: uma parceria entre uma empresa varejista e um negócio social de comércio justo configura uma inovação sustentável? Para abordar essa questão, a qual detém um caráter exploratório, um estudo de caso é proposto sobre o E-Solidário, uma parceria entre a Solidarium e o Walmart Brasil, que juntos têm como objetivo ser o maior canal de comércio justo no Brasil.

O estudo de caso exploratório é recomendado quando o foco da pesquisa consiste em fenômenos contemporâneos dentro do contexto de vida real em comparação a eventos históri$\cos$ (Yin, 2010). As evidências aqui utilizadas foram coletadas em fontes secundárias de informação, mediante consulta a trabalhos acadêmicos realizados sobre as organizações estudadas, assim como consulta a dados disponíveis publicamente em seus websites e em notícias veiculadas pela mídia. $\mathrm{O}$ artigo está dividido em quatro seções, contando com esta introdução. A próxima seção apresenta o referencial teórico, que trata do varejo e do comércio justo e, depois, da inovação de varejo sustentável. Após, consta o estudo de caso, apresentado o negócio social e sua parceria com a grande empresa varejista. Por fim, é elaborada uma discussão relacionando as informações coletadas com os conceitos teóricos apresentados anteriormente, a partir da qual são apresentadas as considerações finais. 


\section{REFERENCIAL TEÓRICO}

\subsection{Varejo e Comércio Justo}

O varejo não é um setor da economia, mas uma atividade de ligação entre o produtor do bem ou do serviço de diversos setores econômicos e o consumidor final (Angelo, 2012). Engloba, portanto, todas as atividades relacionadas com o processo de venda de produtos e os serviços que liguem os produtores aos consumidores finais (Parente, 2000; Kotler, Keller, 2005). Olhando para as contas nacionais, é possível observar alguns números que revelam a importância do varejo no contexto brasileiro. A seção intitulada consumo das famílias, no cálculo do Produto Interno Bruto (PIB), refere-se aos diversos gastos do consumidor final, tais como educação, alimentação, transporte e assistência à saúde. Destes, os que estão diretamente relacionados com o varejo de bens são: alimentação, manutenção do lar, vestuário, higiene e cuidados pessoais e fumo. Os que estão parcialmente relacionados são: compra e reforma do lar e assistência à saúde (compra de medicamentos). Segundo Angelo (2012), estima-se que os itens que se relacionam diretamente com o varejo correspondem a cerca de $35 \%$ da seção de consumo das famílias, a qual, no segundo trimestre de 2011, foi responsável por aproximadamente $60 \%$ do PIB.

O mercado do varejo é formado por um variado conjunto de lojas, empresas, mercadorias e serviços voltados ao consumidor final. Segundo Levy e Weitz (2000), as operações do varejo podem ser separadas em varejo com e sem lojas. Essa classificação ocorre em função da existência de atividades realizadas em ambiente físico específico (varejo com lojas) e de atividades realizadas sem que haja um ambiente físico (varejo sem lojas). Ainda de acordo com os autores supracitados, as lojas físicas diferenciam-se pelo chamado composto de varejo: tipo de mercadoria vendida (alimentos, revenda de automóveis, posto de combustíveis, vestuário etc.), variedade e sortimento da mercadoria comercializada (número de categorias de produtos), nível de atendimento ao cliente e preço da mercadoria. Já as operações sem loja correspondem às atividades de venda direta, vendas por catálogo, máquinas do tipo vending machines e comércio eletrônico (Levy, Weitz, 2000).

Comércio eletrônico, e-commerce ou e-business são termos comumente usados para caracterizar atividades de negócios on-line para produtos e serviços realizados na internet, tanto de modo interempresarial (business-to-business) como entre empresas e consumidor final - business-toconsumer (Rosen, 2000; Schneider, Perry, 2000). A alegação de que o comércio eletrônico é apenas uma ferramenta que aumenta as formas atuais de fazer negócios não é considerada confiável na atualidade (Skeffington, 2000). Seus impactos compreendem os ambientes internos, de mercado e de competitividade das empresas, exercendo também efeito sobre a posição competitiva das mesmas, além de gerar mudanças no comportamento do consumidor e do fornecedor (Pires, Aisbett, 2003).

Suas características permitem que o varejo atue de forma positiva, caso as diretrizes estratégicas da organização se orientem nesse sentido. Por sua proximidade e seu grande nível de interação com o consumidor final, o varejo tem a capacidade de se transformar em um "centro de disseminação de valores para a comunidade" (Parente, 2007, p.22). O varejo pode, também, atuar como "intenso agente modificador em toda a cadeia de valor" ao educar seus consumidores quanto à responsabilidade social, promover causas em sua comunidade, incentivar seus consumidores ao voluntariado, atuar em projetos sociais, receber doações e contribuições dos seus clientes e realizar parcerias com seus fornecedores (Parente, 2007, p. 23).

Associando essas características do varejo com as tendências emergentes de comportamento ético e socialmente responsável nos consumidores finais citados anteriormente (Töpfer, 2002; Andorfer, Liebe, 2012), é possível identificar uma crescente oportunidade estratégica para os varejistas. 
Reinartz et al. (2011) identificaram a responsabilidade social corporativa como uma dimensão potencial para inovações no varejo, com base nos desafios gerados por parte dos consumidores.

\subsection{Inovação de Varejo Sustentável}

A inovação é considerada por alguns autores como a principal forma de superar os concorrentes (Porter, 1980). Quando a empresa inova, crescem suas oportunidades de melhorar sua produtividade e a utilização dos seus recursos. Duas razões importantes para uma empresa buscar a inovação são o aumento da sua produtividade e a vontade de ultrapassar seus concorrentes. O termo inovação remete aos desenvolvimentos teóricos do economista Schumpeter (1997), o qual considerava que os empreendedores inovam à medida que introduzem novas formas de produção, novos produtos e novas maneiras de organização. Corroborando com esse autor, no âmbito dos negócios, o conceito de inovação amplamente aceito é definido como a "implementação de um produto (bem ou serviço) novo ou significativamente melhorado, ou um processo, ou um novo método de marketing, ou um novo método organizacional nas práticas de negócios, na organização do local de trabalho ou nas relações externas..." (OCDE, 2005, p. 55).

Uma inovação sustentável é a que permite a "introdução (produção, assimilação ou exploração) de produtos, processos produtivos, métodos de gestão ou negócios novos ou significativamente melhorados para a organização e que traz benefícios econômicos, sociais e ambientais, comparados com alternativas pertinentes" (Barbieri, 2010, p. 151). Os esforços para esse tipo de inovação procuram compreender as diversas partes interessadas, não só seus clientes e fornecedores. Assim sendo, as empresas com inovações sustentáveis estão atentas aos interesses de stakeholders como a comunidade local e grupos ativistas que lidam com causas como ambientalismo, igualdade de gêneros, trabalho infantil, direitos dos animais e assim por diante.

O conceito de inovação sustentável pode ser aplicado a diversas atividades e setores da economia. Desse modo, o varejo sustentável ou socialmente responsável consiste na atividade varejista que procura manter um relacionamento com todos os seus stakeholders considerando seus interesses (Parente, 2004). No entanto, devido à maior interação com os consumidores finais, as ações estratégicas dos varejistas são fortemente influenciadas por essa proximidade com seus clientes. Enquanto que, no setor industrial, os esforços de inovação tendem a ser intermediados por centros de Pesquisa e Desenvolvimento, os quais produzem inovações estruturais nos produtos, nas atividades varejistas, as inovações costumam ocorrer com maior frequência e menor profundidade, sem esse intermédio dos centros específicos voltados à geração de inovação (Melo, Oliveira e Coelho, 2012). Conforme visto a seguir, o Quadro 1 consiste em um breve resumo comparativo entre as características principais observadas nas inovações nas atividades varejistas e no setor industrial.

Quadro 1: Inovações no varejo e na indústria.

\begin{tabular}{|l|l|}
\hline Inovação no varejo & Inovação na indústria \\
\hline Foco em melhoramentos diários (incrementais) & Foco em mudanças em longo prazo (radicais) \\
\hline Busca por mudanças em curto prazo & Busca por mudanças em longo prazo \\
\hline Reduções de custo & Aumento de produtividade/desempenho \\
\hline Aumento de vendas & Novas tecnologias \\
\hline Inovações em aspectos de menor risco & $\begin{array}{l}\text { Inovação como investimento para a prosperidade da } \\
\text { organização }\end{array}$ \\
\hline Caráter informal & Estrutura de Pesquisa \& Desenvolvimento \\
\hline
\end{tabular}

Fonte: Melo, Oliveira e Coelho, 2012. 
As inovações no varejo acontecem com regularidade mediante melhoramentos incrementais nas operações, os quais são alcançados com reduções de custos e aumentos na eficiência dos processos de logística. Ademais, também são representativas as inovações de marketing, como a "criação de produtos, marcas, formatos e soluções estratégicas referentes à segmentação, posicionamento, relacionamento, entre outros aspectos" (Melo, Oliveira e Coelho 2012, p. 58). Conjugando os conceitos apresentados, é possível considerar que uma inovação de varejo sustentável represente uma implementação de um produto (bem ou serviço), um processo, um método de marketing ou um novo método organizacional novo ou significativamente melhorado nas atividades varejistas, de modo que traga benefícios econômicos, sociais e ambientais, comparados com alternativas pertinentes, considerando os interesses das partes interessadas.

Nesse âmbito, o presente estudo busca relacionar o comércio justo com o varejo sustentável, sendo este definido como uma parceria comercial baseada no diálogo, na transparência e no respeito, que busca maior equidade no comércio internacional. Ele contribui para o desenvolvimento sustentável, oferecendo melhores condições comerciais e garantindo os direitos dos produtores e trabalhadores marginalizados - especialmente em países em desenvolvimento (Fairtrade International, 2013). Para explorar essa relação, na próxima seção, será apresentada uma organização de negócio social especializada em comércio justo, a qual realizou uma parceria com uma empresa varejista de grande porte e atuação.

\section{ESTUDO DE CASO}

\subsection{Solidarium Comércio Justo}

Insatisfeito com o modelo de negócios tradicional das empresas maximizadoras de lucro e tendo experimentado a constante luta pela sobrevivência no terceiro setor, o jovem empreendedor curitibano Tiago Dalvi investiu em um modelo intermediário que gerasse lucro e dividendos sociais. Segundo ele, a motivação para os negócios sociais veio aos 20 anos, ao descobrir que no Brasil havia cerca de 8,5 milhões de artesãos, dos quais 2 milhões viviam em condição de extrema pobreza, sem ao menos conseguir vender o que produziam (Veja, 2012). Como empreendedor social, enfrentou o grande desafio de combinar benefícios sociais com lucratividade e alcançar escala.

A Solidarium surgiu em 2006 como um programa integrante da Organização Não Governamental (ONG) Aliança Empreendedora, na qual trabalhavam Tiago Dalvi e outros colegas de curso. No fim daquele ano, o programa conseguiu arrecadar $R \$ 27.000,00$ com a venda de artefatos de Natal produzidos pelo grupo Zumbi Arte. As 23 artesãs da Associação dos Empreendedores Zumbi dos Palmares, da periferia de Curitiba, tiveram de produzir 3 mil unidades de anjos para a hidrelétrica Itaipu Binacional em 25 dias. Essa venda foi crucial por dois motivos: mostrou que havia mercado e capacidade produtiva para atendê-lo e permitiu enquadrar a Solidarium como microempresa pelo SIMPLES. Após pesquisarem sobre diversos modelos de organizações de comércio justo, no começo de 2007 foi aberta uma loja pequena em um shopping em Curitiba. Esta acabou gerando um custo fixo alto devido a dificuldades logísticas (custo de transporte e de monitoramento), apesar da isenção de impostos cedida pelo shopping. O fechamento da loja em dezembro de 2008 foi acompanhado por uma reflexão sobre o formato da empresa e sobre o crescente interesse em aumentar a escala de vendas dos produtos (Época, 2010; Zechner, 2010). Segundo a Solidarium, a empresa quase faliu por não possuir uma marca reconhecida, produtos muito bons e capital para manter sua estrutura (Solidarium, 2013). 
A empresa, hoje, é uma sociedade limitada com um objetivo maior do que exclusivamente gerar lucros aos seus acionistas. Sua missão é construir um Brasil de verdade, rico em diversidade e não desigualdade. Com a visão de tirar mais de 10.000 pessoas da pobreza em cinco anos e criar uma revolução no mercado nacional, a Solidarium desenvolve canais de comercialização inovadores e incomparáveis para os produtos de seus artesãos. Seu diferencial é disponibilizar acesso a melhores condições de troca entre pequenos produtores e consumidores, configurando-se, assim, sob os moldes do conceito de comércio justo. Nos últimos quatro anos, a empresa foi responsável por ligar mais de 1.600 produtores locais, distribuídos em 12 estados brasileiros e organizados em 44 cooperativas e associações, a cerca de 170 lojas, incluindo grandes redes varejistas como Walmart, Tok \& Stok e Lojas Renner. Além do acesso ao varejo, proporcionou vendas especificamente para grandes empresas, como Natura, Esso, Itaipu, e centenas de outras pequenas e médias empresas (Solidarium, 2013; Ronca, 2010; Zechner, 2010).

Seus artesãos produzem bons produtos, com design e preço competitivo, mas pecam na falta de conhecimento em promoção e vendas. Os produtos variam de bolsas a chinelos e porta-canetas e hoje são produzidos por estúdios de design e confeccionados por cerca de 270 produtores de baixa renda. Tratam-se, em sua maioria, de mulheres, organizadas em associações, cooperativas ou grupos de trabalho, que recebem até três vezes e meia o que ganhariam se produzissem sozinhas (PEGN, 2012). Os produtos estão disponibilizados em prateleiras e estandes dos parceiros da empresa, mas é no e-commerce do grupo Walmart que o negócio tem se mostrado viável financeira e institucionalmente. Nele são reduzidas restrições às economias de escala, como limite de estoque e dificuldade logística, permitindo projeções cada vez maiores do alcance da empresa. De fato, a parceria Solidarium/Walmart planeja ser o maior canal de comércio justo no Brasil e massificar as vendas dos produtos, sem que haja perda da qualidade (Época, 2010).

Com o aprendizado acumulado nesses seis anos de existência, a empresa chegou ao seu formato atual da solidarium.net, um modelo de negócios diferente do que é comumente visto em lojas de comércio eletrônico. A Solidarium oferece aos artesãos e às cooperativas associadas à empresa a representação para articulação de vendas corporativas com grandes clientes varejistas já citados anteriormente, melhor acesso a matérias-primas e, também, orientação e serviço de design, sem que seja cobrado nenhum custo adicional. De fato, a Solidarium não cobra do artesão taxa de cadastro, anuidade ou mensalidade, mas cobra uma comissão de $10 \%$ sobre cada venda realizada. Desse modo, o crescimento da empresa fica diretamente atrelado ao crescimento do artesão, sem que haja uma diferença exacerbada que prejudique a capacidade do artesão de manter seu negócio. Segundo a própria empresa, ela quer criar "um verdadeiro movimento para combater a pobreza promovendo o acesso a mercado" (Solidarium, 2013).

Tiago confirma a tese do escritor norte americano Bruce Tulgan, de que os jovens nascidos nas décadas de 1980 e 1990 empreendem por paixão: para se sentir realizado prefere fazer coisas que "façam a diferença". Além disso, o empreendedor acredita que é possível obter lucro combatendo a pobreza: a expectativa de faturamento para 2012 da sua empresa era de 1 milhão de reais (Veja, 2012). A lógica da criação de valor no seu caso se distancia tanto das empresas tradicionais, que visam a um menor excedente do consumidor e maior excedente do produtor possível, quanto da lógica das organizações do terceiro setor. Segundo o fundador Tiago Dalvi, "Nossos artigos são até $50 \%$ mais caros, mas $40 \%$ do que recebemos vão para o produtor. Quanto mais lucramos, mais pessoas tiramos da pobreza" (PEGN, 2011). Um projeto da Solidarium é de que, em breve, os próprios produtores sejam sócios da empresa, de modo que possam retirar dividendos e assim incrementar sua renda (Ronca, 2010). 


\subsection{Walmart Brasil e o E-Solidário}

O Walmart, de acordo com a lista 500 da revista Fortune, é a maior empresa do mundo, com 469,2 bilhões de dólares em receitas e lucro de aproximadamente 17 bilhões de dólares (Fortune, 2013). Está presente em 27 países, com cerca de 10 mil unidades, atuando sob 69 bandeiras e empregando mais de 2,2 milhões de funcionários (Walmart, 2013). Com operações no Brasil há 18 anos, a empresa registrou em 2011 um faturamento de 23,4 bilhões de reais e alcançou a posição de 17a maior empresa atuando no país, pelo critério de vendas líquidas, com cerca de 7,6 bilhões de dólares (Exame, 2013). Treze anos após começar suas operações no Brasil, a empresa lançou o site walmart.com.br, que hoje tem 80 mil itens em seu portfólio, distribuídos em 17 categorias (Walmart, 2013).

Nos anos de 2010, 2011 e 2012, o comércio eletrônico da empresa obteve reconhecimento nacional, sendo eleita a melhor loja brasileira pela e-bit (empresa brasileira referência no fornecimento de informações sobre e-commerce nacional). O Walmart ganhou a categoria mais importante, o Diamante da e-bit, no Prêmio Excelência em Qualidade Comércio Eletrônico Business-to-Consumer (Walmart, 2013).

Nesse meio tempo, a empresa no Brasil cresceu no campo da sustentabilidade empresarial, incluindo os objetivos de sustentabilidade e responsabilidade social corporativa na sua estratégia de negócio. Segundo o relatório de sustentabilidade de 2012 da empresa, a remuneração dos principais executivos do Walmart Brasil está atrelada a resultados financeiros e também às iniciativas de sustentabilidade, representadas pelas metas ambientais de produtos comercializados, que são referentes a impactos no clima, ao uso de energia e à geração de resíduos (Relatório de sustentabilidade, p.16, 2012 in Walmart, 2013).

Dentre as 41 iniciativas para alcançar os objetivos estratégicos no Brasil, é possível destacar algumas que se relacionam diretamente com o que é comentado na literatura sobre a vocação natural do varejo para a sustentabilidade e responsabilidade social corporativa (Parente, 2007). A empresa tem quatro objetivos que correspondem à característica "ser um centro de disseminação de valores para a comunidade" (Parente, 2007, p.22): capacitar jovens para o trabalho, contribuir com o desenvolvimento local, ampliar a inclusão econômica e agir em benefício da comunidade.

A iniciativa de "ser referência e estimular ações sustentáveis" é uma das correspondências à característica de agente modificador, observada na influência exercida pela empresa sobre seus fornecedores para que adotem metas e prazos para o desenvolvimento de produtos mais sustentáveis, que tenham, por exemplo, suas embalagens reduzidas (Relatório de sustentabilidade, p.21, 2012 in Walmart, 2013). O Walmart também participa de fóruns sobre biodiversidade, mudanças climáticas e reciclagens; estimula o voluntariado no "dia da comunidade"; promove causas em sua comunidade, atuando em projetos sociais sobre os temas juventude e trabalho, desenvolvimento local e geração de renda; e promove doação a bancos de alimentos.

A iniciativa de "trabalhar por um Brasil sem miséria" traduz-se em três vertentes: promover a comercialização da produção da agricultura familiar oriunda de comunidades carentes, por meio do Clube dos Produtores; capacitar trabalhadores e dar oportunidades de emprego aos cadastrados no Ministério do Trabalho, mediante as ações da Escola Social do Varejo; e prover meios para a promoção de uma economia para todos, com a criação de um espaço de comercialização para empreendimentos solidários, o E-Solidário (Relatório de sustentabilidade, p.22, 2012 in Walmart, 2013).

O E-Solidário é um canal de comercialização eletrônico fruto da parceria que data de 2010 entre o Walmart Brasil e a Solidarium. Além de ser uma página à parte no website do Walmart Brasil - http://www.walmart.com.br/e-solidario -, ele representa a inclusão de um dos seis 
temas da nova categoria de produtos na loja on-line usual da empresa - http://www.walmart. com.br/departamento/produtos-sustentaveis/1916. Os produtos sustentáveis são, hoje, em torno de 500 itens, distribuídos em seis temas, que "ajudam o consumidor a identificar quais os principais benefícios agregados": cosméticos orgânicos e naturais, energia, matéria-prima, transporte alternativo, redução de resíduos e o E-Solidário (Relatório de sustentabilidade, p.57, 2012 in Walmart, 2013). São cerca de 140 itens, produzidos por mais de 150 artesãos de comunidades em 12 estados brasileiros. Além do acesso desses pequenos empreendedores aos mercados consumidores e dos benefícios diretos desse acesso - aumento de demanda, renda e oportunidades de trabalho -, o Walmart possibilita o pagamento antecipado de $50 \%$ por encomenda feita, uma inovação possível mediante negociação da Solidarium com a empresa varejista (Walmart, 2013).

$\mathrm{O}$ alinhamento estratégico da inserção da responsabilidade social e ambiental com a empresa é comentado a seguir pelo diretor de e-commerce do Walmart Brasil, Flávio Dias: "vender produtos mais sustentáveis e com apelo social e, com isso, contribuir para o desenvolvimento das comunidades se encaixa perfeitamente na nossa maneira de ver a sustentabilidade de maneira ampla, completamente inserida no negócio" (Walmart, 2013). O mix de produtos do E-Solidário ainda é pequeno, considerando que é necessário um tempo para estruturar a produção a fim de acompanhar o crescimento da demanda, mas o diretor revela expectativas altas quanto à parceria, afirmando que espera triplicar o número de itens à disposição na linha.

Uma característica inovadora nos produtos da linha E-Solidário é a inclusão da descrição "Histórico do Produto" nos detalhes do produto, suprindo o interesse emergente dos consumidores nos bastidores da produção dos bens a serem comprados (Töpfer, 2002). Nas imagens a seguir, constam exemplos dessa inovação na descrição de produto. A Figura 1 reproduz todas as descrições que constam na descrição do produto tomado como exemplo.

Figura 1: Detalhes do produto exemplo 1

(0) Características do produto

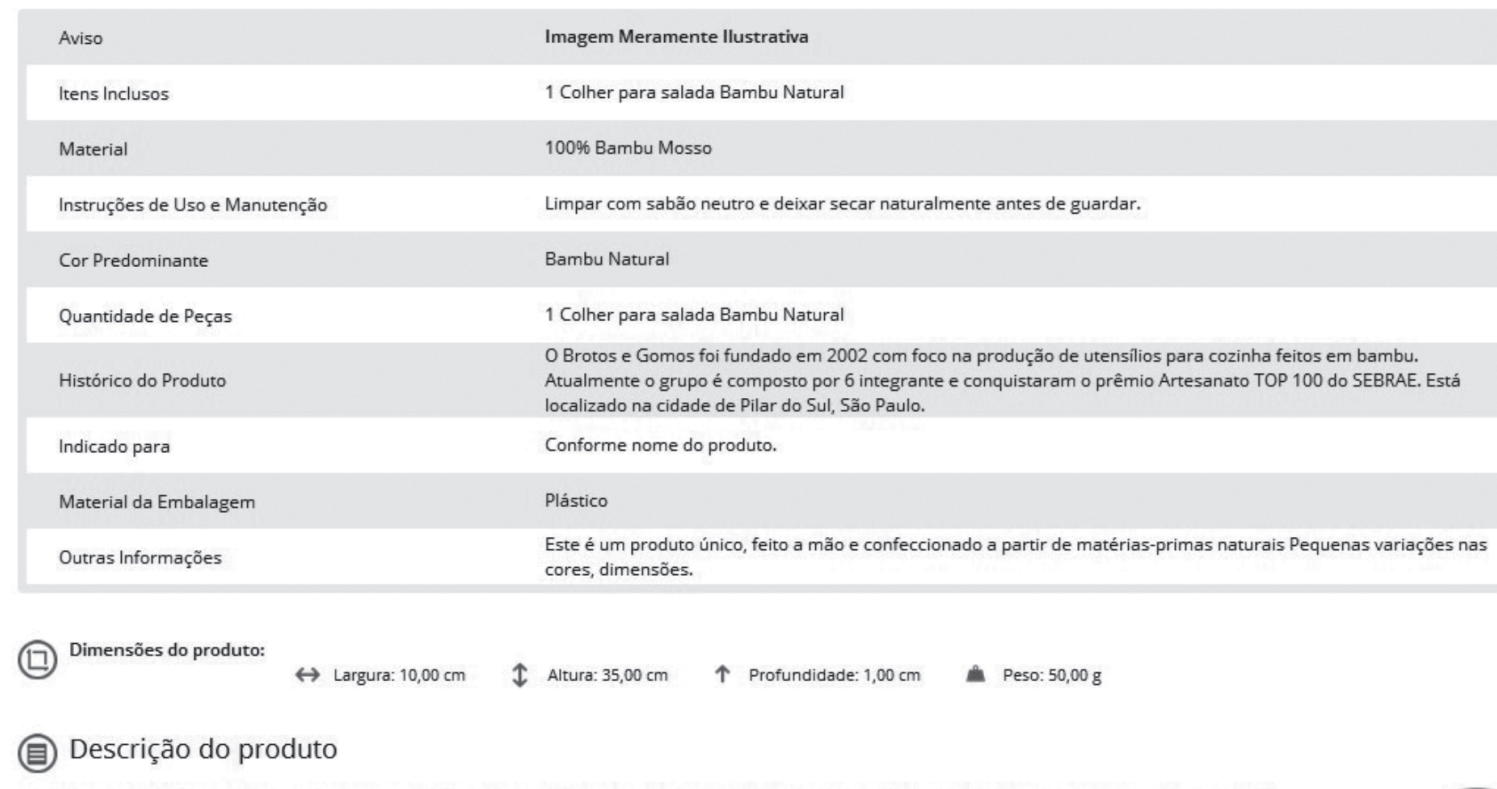

Colher para salada feita de bambu mosso, com brilho natural, não acumula sujeira, inodoro, não deixa e nem guarda sabor dos alimentos, alta resistência. Fonte: Walmart (2013). Descrição realçada pelos autores. 
A título de explanação, na Figura 2, exposta a seguir, é evidenciada apenas a descrição do histórico do produto. Conforme é possível observar, a empresa não poupa detalhes para descrever o histórico de cada produto.

Figura 2: Detalhes do produto exemplo 2

\begin{tabular}{|c|c|}
\hline Quantidade de Peças & 1 Copo Mocado (Marrom) \\
\hline Histórico do Produto & $\begin{array}{l}\text { Iniciada em } 19 \text { de setembro de 1993, a Cerâmica Serra da Capivara foi um projeto da FUMDHAM - Fundação Museu } \\
\text { do Homem Americano na pessoa da Prof. Dra. Niéde Guidon, com objetivo de implantação de uma cultura se } \\
\text { sobrevivência diferenciada, que respeitasse as condiçães de meio ambiente e resgatasse o povo da caatinga ao seu } \\
\text { habitat natural. Para viverem da cerâmica em suas terras e ao mesmo tempo resguarda o entorno da Unidade de } \\
\text { Conservação - Parque Nacional Serra da Capivara. Grandes mudanças em 2007: tivemos um grande projeto da } \\
\text { NATURA, que mudou a vida de toda a comunidade para sempre. Com grandes vendas durante } 5 \text { meses, a } \\
\text { comunidade investiu em melhorias habitacionais, a oficina se equipou e conseguiu, depois de } 14 \text { anos, fazer com que } \\
\text { todos acreditassem que é possivel sim mudar a vida para melhor. As dificuldades até reapareceram, mas } \\
\text { acreditamos que nosso produto tem qualidade e pracurar todos os dias em acreditar sempre. Entramos no mercado } \\
\text { etemos condições. Em 2008, CEBEDES reconhece Cerâmica Artesanal Serra da Capivara, como o melhor projeto de } \\
\text { SUSTENTABILIDADE do Brasil. }\end{array}$ \\
\hline Indicado para & Para o café da manhã, ou lanche da tarde, para beber, suco água ou leite. \\
\hline Tamanho & Altura $9,5 \mathrm{~cm}$, Largura $7,5 \mathrm{~cm}$ \\
\hline
\end{tabular}

Fonte: Walmart (2013). Descrição realçada pelos autores.

\section{DISCUSSÃO}

A parceria entre a Solidarium e o Walmart Brasil rende benefícios para o alcance das estratégias das duas empresas. Por um lado, há o negócio social promissor, cujo impacto social positivo configura sua razão de ser. Desde sua fundação, a Solidarium conquistou diversos prêmios de reconhecimento nacional, como o Empreendedor Social de Sucesso 2011, concedido pela Revista Pequenas Empresas e Grandes Negócios, e de reconhecimento internacional, conferidos por instituições como Artemisia, Ashoka, Fundação Ebay, St. Gallen Symposium e Unreasonable Institute. Com o objetivo de levar esse impacto positivo, mediante o melhor acesso aos mercados consumidores, aliado às qualidades do comércio justo, a Solidarium viabiliza o alcance das suas diretrizes estratégicas fortalecendo essa parceria com uma grande empresa varejista, de destaque nacional e internacional.

Por outro lado, há o Walmart, uma grande empresa global, com forte atuação no país. No seu país de origem (Estados Unidos), tem um histórico de pressões e acusações, exercidas por sindicatos de empregados e entidades representativas do comércio. Existe, também, registro de críticas feitas por partes dos fornecedores, que se viam cada vez mais pressionados por margens mais baixas para cumprir com os preços baixos oferecidos pela varejista, de modo que adotavam condições de trabalho precárias e até ilegais aos seus funcionários (Ming, 2006; Rosenburg, 2007). Para reverter esse quadro prejudicial à marca e reputação da empresa, sob orientação internacional, as mudanças vieram do topo e chegaram até o Walmart Brasil. Srour (2012, p. 44) defende que, mais do que publicidade enganosa acerca da sustentabilidade, a empresa adotou verdadeiras medidas impactantes, como sua coligação com o grupo Pão de Açúcar e o Carrefour, em junho de 2009, para anunciar a suspensão da compra de produtos bovinos de 11 frigoríficos do Pará, que estavam sob suspeita de trazer carne de áreas desmatadas da Amazônia. Sua parceria com a Solidarium permite esforços no cumprimento de 11 das suas 41 iniciativas para alcance de seus objetivos estratégicos, conforme é possível observar no Quadro 2. 
Quadro 2: Benefícios estratégicos para o Walmart oriundos da parceria com a Solidarium

\begin{tabular}{|l|l|}
\hline Iniciativa Walmart & Como a parceria com a Solidarium colabora \\
\hline Crescer de forma sustentável no país & Crescimento sustentável do canal eletrônico \\
\hline Trabalhar por um Brasil sem miséria & Acesso aos mercados consumidores via E-Solidário \\
\hline Privilegiar mão de obra local & E-Solidário com produtos de comunidades brasileiras \\
\hline Conceder benefícios além da legislação & Pagamento antecipado de 50\% por encomenda feita \\
\hline Orientar para a sustentabilidade & Canal de informação específico sobre sustentabilidade no site \\
\hline Realizar compras responsáveis & Solidarium tem produtos certificados pela Fairtrade International \\
\hline Estimular os pequenos e médios produtores & Produtos de 150 artesãos de comunidades em 12 estados brasileiros \\
\hline Incentivar produtos mais sustentáveis & Solidarium tem produtos certificados pela Fairtrade International \\
\hline Orientar os consumidores & $\begin{array}{l}\text { Canal de informação específico sobre sustentabilidade no site, inclu- } \\
\text { são da descrição “Histórico do Produto" nos produtos do E-Solidário }\end{array}$ \\
\hline Promover o consumo consciente na internet & $\begin{array}{l}\text { Canal de informação específico sobre sustentabilidade no site, inclu- } \\
\text { são da descrição “Histórico do Produto" nos produtos do E-Solidário }\end{array}$ \\
\hline Ampliar a inclusão econômica & Produtos de 150 artesãos de comunidades em 12 estados brasileiros \\
\hline Fonte: Elaboração própria. &
\end{tabular}

\section{CONSIDERAÇÕES FINAIS}

A pergunta de partida do presente artigo era se uma parceria entre uma empresa varejista e um negócio social de comércio justo poderia configurar uma inovação sustentável. Verificou-se na literatura que a inovação no varejo pode ocorrer, dentre outras formas, mediante inovações de marketing, como com a criação de produtos, marcas, formatos e soluções estratégicas referentes à segmentação, ao posicionamento e ao relacionamento, entre outros aspectos. Com a parceria entre o Walmart Brasil e a Solidarium, foi observada a introdução de um novo canal de comércio e um novo tema na também nova categoria de produtos "Produtos Sustentáveis". A parceria com a Solidarium permitiu um novo posicionamento de caráter sustentável pelo Walmart: o engajamento com responsabilidade socioambiental, o empoderamento de iniciativas comunitárias, os melhoramentos nas condições de troca e assim por diante.

Observou-se, também, na literatura que uma inovação sustentável é aquela que permite a introdução de inovação na organização de modo que traga benefícios econômicos, sociais e ambientais, comparados com alternativas pertinentes. A partir disso, uma conjunção de conceitos foi proposta: a Inovação de Varejo Sustentável. Foi possível identificar ganhos de imagem e reputação no posicionamento mais sustentável do Walmart Brasil como um todo (Srour, 2012), algo já previsto em iniciativas de responsabilidade social no varejo (Parente, 2000; Srour, 2012). De acordo com Parente (2007), "a associação a compromissos de responsabilidade social gera benefícios de longo prazo, como valorização da imagem institucional e da marca, maior lealdade do consumidor, maior capacidade de recrutar e manter talentos e melhoria do diálogo com os públicos de interesse da empresa" (stakeholders). No entanto, não foram observados ganhos de imagem especificamente relativos à parceria Solidarium e Walmart Brasil. Apesar disso, foi identificada a relação da Solidarium com 11 das 41 iniciativas do Walmart Brasil para alcance de seus objetivos estratégicos, os quais colaboram para a gestão da reputação da empresa varejista.

Como se trata de um estudo de caso elaborado apenas por meio de fontes de evidências secundárias, não é possível discorrer sobre as limitações do presente artigo sem citar esse fato. Dispor de outras fontes de coleta de evidências e realizar a triangulação de técnicas de coleta de dados ou mesmo de análise consistem nas as recomendações primordiais para estudo futuros. No entanto, é possível afirmar que a consulta à literatura, a identificação de conceitoschave e a construção de pontos de convergência entre eles e as observações do estudo de caso conferem ao presente artigo um resultado satisfatório quanto às suas contribuições teóricas. As 
implicações práticas concernem ao incentivo a parcerias de interesses semelhantes, conforme os identificados aqui, de modo que ambos os lados se beneficiem.

\section{REFERÊNCIAS}

ANDORFER, V. A.; LIEBE U. Research on Fair Trade Consumption - A Review, Journal of Business Ethics 6, 415-435, 2012.

ANGELO, C. O varejo no Brasil e no mundo. In: Manual de Varejo no Brasil, Orgs.: Angelo, C.; Nielsen, F.; Fouto, N. São Paulo: Saint Paul Editora, 2012.

BARBIERI, José Carlos; Freitas Gouveia de Vasconcelos, Isabella; Andreassi, Tales; Carvalho de Vasconcelos, Flávio. Inovação e sustentabilidade: novos modelos e proposições. RAE Revista de Administração de Empresas, vol. 50, núm. 2, abril-junho, p. 146-154, 2010.

ÉPOCA - Revista Época Negócios. Costura social. 14 de Out. 2010. Disponível em: http:// epocanegocios.globo.com/Revista/Common/0,,EMI177064-16642,00-COSTURA +SOCIAL.html

EXAME - Revista Exame. AS 100 MAIORES EMPRESAS DO BRASIL - 2012. Acesso em: 15/05/2013. Disponível em: http://exame.abril. com.br/negocios/empresas/melhores-e-maiores/ranking/2012/.

FAIRTRADE INTERNATIONAL. Fair Trade Glossary. Acesso em: 15/05/2013. Disponível em: http://www.fairtrade.net/.

FORTUNE. Fortune 500. Acesso em: 15/05/2013. Disponível em: http://money. cnn.com/magazines/fortune/fortune500/.

GANESAN, S.; GEORGE, M.; JAP, S.; PALMATIER, R.; WEITZ, B. Supply Chain Management and Retailer Performance: Emerging Trends, Issues, and Implications for Research and Practice, Journal of Retailing, 85: 1, p. 84-94, 2009.

HANDELMAN, J.; ARNOLD, S. The Role of Marketing Actions with a Social Dimension:
Appeals to the Institutional Environment. Journal of Marketing Vol. 63, No. 3, p. 33-48, 1999.

KOTLER, P.; KELLER, K. Administração de marketing. 12 ed. São Paulo: Pearson Prentice Hall, 2005.

LEVY, M.; WEITZ, B. Administração de varejo. 3. Ed. São Paulo: Atlas, 2000.

MELO, P.; OLIVEIRA, M.; COELHO, D. Inovação no Varejo. In: Manual de Varejo no Brasil, Orgs.: Angelo, C.; Nielsen, F.; Fouto, N. São Paulo: Saint Paul Editora, 2012.

MING, C. Nobel para a Walmart. O Estado de S. Paulo, 24 out. 2006.

OCDE - Organização para a Cooperação e Desenvolvimento Econômico. Manual de Oslo, 3. ed., 2005.

PARENTE, J. Varejo no Brasil: gestão e estratégia. São Paulo: Atlas, 2000.

\section{Responsabilidade social no va-}

rejo: conceitos, estratégias e casos no Brasil. São Paulo: Saraiva, 2004.

\section{Varejo e a responsabilidade}

social [recurso eletrônico]: visão estratégica e práticas no Brasil. Gley Costa, Jacob Jacques Gelman. - Dados eletrônicos. - Porto Alegre: Artmed, 2007.

PEGN - Revista Pequenas Empresas \& Grandes Negócios. Eles querem mudar o mundo. Agosto, 2011.

Eles têm menos de $\mathbf{3 0}$ anos e estão mudando o mundo. Acesso em: 11 de mar. 2012. Disponível em: http://revistapegn.globo.com/Revista/Common/0,,EMI102 891-17171-1,00-ELES+TEM+MENOS+DE+ANOS+E+ESTAO+MUDANDO+O+ MUNDO.html

PIRES, G.; AISBETT, J. The relationship between technology adoption and strategy in business- 
to-business markets The case of e-commerce. Industrial Marketing Management 32, p. 291300m 2003

PORTER, M. Competitive Strategy: Techniques for Analyzing Industries and Competitors. New York: The Free Press, 1980.

REINARTZ, Werner; DELLAERT, Benedict; KRAFFT, Manfred; KUMARD, V.; VARADARAJAN, Rajan. Retailing Innovations in a Globalizing Retail Market Environment. Journal of Retailing, 87S, 1, p. 5366, 2011.

RONCA, C. E. F. Estudo sobre a Empresa Social como uma ferramenta para se alcançar a prosperidade duradoura. $49 \mathrm{p}$. Trabalho de Conclusão de Curso (MBA em Gestão de Sustentabilidade) - Programa FGV Management, Fundação Getúlio Vargas, São Paulo, 2010.

ROSEN, A. The e-Commerce question and answer book: a survival guide for business managers. NY: American Management Association, 2000.

ROSENBURG, C. Por dentro da revolução verde. Época Negócios, p. 102-113, set. 2007.

SCHNEIDER G.; PERRY J. Electronic commerce. Cambridge: Course Technology - ITP, 2000.

SCHUMPETER, J. A. Teoria do desenvolvimento econômico. São Paulo: Editora Nova Cultural, 1997.

SKEFFINGTON R. Toll goes the extra mile. Business Review Weekly; 8:29, Setembro, 2000.

SOLIDARIUM. Disponível em: www.solidarium. net/sobre. Acesso em: 20/06/2013.

SROUR, R. A Ética nos negócios de varejo. In: Manual de Varejo no Brasil, Orgs.: Angelo, C.; Nielsen, F.; Fouto, N. São Paulo: Saint Paul Editora, 2012.

TÖPFER, K. Keynote Speech. Launch of the UNEP/SETAC Life Cycle Initiative, UNEP, Prague, 2002.
VEJA - Revista Veja. Entre mudar o mundo e ganhar dinheiro, por que não optar pelos dois? Veiculada dia 11 de mar. 2012. Disponível em: http://veja.abril.com.br/noticia/ educacao/entre-mudar-o-mundo-e-ganhar-dinheiro-por-que-nao-optar-pelos-dois.

WALMART. Walmart Brasil. Disponível em: http://www.walmartbrasil.com.br/sobre-o -walmart/no-brasil/. Acesso em: 18/06/2013.

YIN, R. K. Estudo de caso: planejamento e método. 4. ed. Porto Alegre: Bookman, 2010.

ZECHNER, T. C. Estratégias de Desenvolvimento Territorial Sustentável: o Caso da Empresa Social Solidarium e a Experiência do arranjo Socioprodutivo de Base Comunitária do Rio Sagrado (Morretes - PR) Dissertação (Mestrado em Desenvolvimento Regional) - Centro de Ciências Humanas e da Comunicação, Universidade Regional de Blumenau, Blumenau, 2010. 